\title{
Prevalence and Manifestations of Hypothyroidism among Population of Hyderabad, Sindh, Pakistan
}

Naheed Shah ${ }^{1}$, Tahira Jabeen Ursani ${ }^{1}$, Nadir Ali Shah ${ }^{1}$ and Hafiz Muhammad Zeeshan Raza ${ }^{2 *}$

1. Department of Zoology, University of Sindh, Jamshoro, 76080, Sindh-Pakistan

2. Genomics and Computational Biology Laboratory, Biosciences Department, COMSATS University Islamabad, Sahiwal Campus, Punjab-Pakistan

*Corresponding author's email: hafizraza26@gmail.com

Citation

Naheed Shah, Tahira Jabeen Ursani, Nadir Ali Shah and Hafiz Muhammad Zeeshan Raza. Prevalence and Manifestations of Hypothyroidism among Population of Hyderabad, Sindh, Pakistan. Pure and Applied Biology. Vol. 10, Issue 3, pp668-675. http://dx.doi.org/10.19045/bspab.2021.100069

\begin{tabular}{llll}
\hline \hline Received: 01/08/2020 & Revised: 29/10/2020 & Accepted: 09/11/2020 & Online First: 24/11/2020 \\
\hline
\end{tabular}

\section{Abstract}

The major endocrine gland is the thyroid gland, which secretes vital hormones like T3 (triiodothyronine), T4 (thyroxine) and TSH (thyroid stimulating hormone) which are the key performer in the maintenance of body's homeostasis of the body. The thyroid related disorders are rapidly increasing around the globe due to deficiency of iodine and other factors. There is also a high prevalence of thyroidal diseases in Pakistan. Although it is not a life threatening disorder, but if it is overlooked and remained untreated, it may develop into life threatening disorders like cancer. Moreover, as thyroid gland is a malfunctioned gland and greatly affects various functions of many other body parts which depend on the hormonal secretion of thyroid hormones for performing their normal functions. To assess the thyroidal disorder (hypothyroidism) situation of in Sindh, this study was conducted to evaluate the prevalence of hypothyroidism in population of Hyderabad. Hypothyroid diagnosed individuals were enrolled, and their serum thyroid hormones level, signs, symptoms, and clinical manifestations were observed. Thyroid function test (TFT) was done using radioimmunoassay techniques ELISA, Immunoassay test (RIA) kits. Different clinical manifestations, signs and symptoms presented by the patients were also analyzed, and disease was determined in relation to those symptoms. High prevalence of hypothyroidism was found in females. In hypothyroid patients, goiter was observed to be $27 \%$, Hashimotos to be $9 \%$, Thyroid Cancer to be $10 \%$, and Iodine Deficiency to be $88 \%$ with high prevalence in 21 years to 29 years age group.

Keywords: Endocrine gland; Goiter; Hypothyroidism; Hashimotos; TSH; T3; T4; Thyroid Cancer

\section{Introduction}

The disturbance in the normal thyroid function is usually caused by perturbation in HPT (hypothalamus-pituitary-thyroid) axis, which eventually affects all mechanisms occurring in the body [1]. All across the globe, diabetes mellitus and ailments related to thyroidal function are high prevalent glandular disorders independent of age and gender [2, 3]. Thyroidal dysfunction may be subclinical, asymptomatic, characterized by irregularities of thyroid hormone level with 
normal levels of T3 and T4, and abnormal TSH level. Clinically symptomatic thyroid dysfunction is characterized by abnormal serum levels of T3 and T4 respectively [4]. Furthermore, thyroid dysfunctions include goiter, subclinical phases, Grave's disease, Hashimoto's thyroiditis, thyroid cancer and iodine deficiency disorders [5]. All of these disorders have been documented in various reports in more than 110 countries worldwide, risking a population of approximately 1.6 billion [6].

For the normal synthesis, secretion, and maintenance levels of thyroid hormones T3 and T4, iodine is an integral ingredient [7]. Food and water are the chief sources of iodine supplied to the thyroid gland to function normally, the deficiency of iodine in these sources lead towards the development of iodine deficiency disorders like cretinism, hypothyroidism, and goiter etc. [8]. The prevalence of iodine deficiency is reported in more than one third the population of the world [9]. In areas with a severe deficiency of iodine, the rate of prevalence of goiter reaches up to $80 \%$ [10]. In South Asian countries, deficiency of iodine is the reason for higher rates of thyroid disorders [9]. In most cases, it is observed that only because of the goiter the physician recommends the screening of for thyroid disorders. Among the adult population of India prevalence of goiter has been reported to be $12 \%$ [11] and in children up to $23 \%$ [12].

In Pakistan, clinical and subclinical hypothyroidism prevails up to $4.1 \%$ in adults, and $5.4 \%$ in children and high prevalence of hypothyroidism and hyperthyroidism are found in females compared to males [13]. Abnormalities in thyroid function, especially in subclinical hypothyroidism, are linked with a high risk of coronary artery disease and atherosclerosis [14]. Prevalence of arrhythmias related to supra-ventricular, increased heart rate, and enhanced mass left ventricular has been associated with hypothyroidism [15]. Coagulation abnormalities in state of thyroid dysfunction, whether hyperthyroidism or hypothyroidism has also been observed [16]. Many other anomalies are also associated with thyroid disorder, including cardiovascular hemodynamics changes, abnormalities in diastolic function, endothelial dysfunction, hypercholesterolemia, and hyperhomocysteinemia [17].

In children and adolescents, residing in areas of iodine-sufficient thyroablative therapy and autoimmune thyroid disease are the foremost causes of hypothyroidism [18]. If the thyroidal disorders remain untreated, they can seriously affect whole mechanisms of body especially the cardiovascular system [19]. Therefore, in order to cope with the consequences of thyroid disease, public awareness regarding thyroidal ailments and importance of iodine intake is necessary. This research study aims at evaluating prevalence, clinical manifestation and pathophysiological features of hypothyroidism in population.

\section{Materials and Methods}

It was a prospective study comprised of 204 hypothyroid patients to check prevalence, clinical manifestation and pathophysiological features of hypothyroidism in them who visited various private and government hospitals of Hyderabad, Sindh, Pakistan. The study setting was different Hospitals of Hyderabad, including Civil Hospital Hyderabad, Aga Khan Hospital, NIMRA Hospital Hyderabad, Shah Bhitai Hospital Hyderabad, and Sindh Government Hospital Qasimabad, Hyderabad, after seeking approval by the governing bodies and ethics committee of the hospitals.

\section{Data collection}

The data for the study was collected by using a specially designed questionnaire, $x$-rays reports, thyroid ultrasound reports, and other laboratory test reports in order to analyze the 
hypothyroid patients. The questionnaire was designed to collect the information by interviewing patients about their general sociodemographic data, including weight, age, height, signs and symptoms, clinical manifestations, etc. Body mass index was calculated according to the criteria by WHO using the weight of females in kilograms divided by taking the height square in meters $\left(\mathrm{Kg} / \mathrm{m}^{2}\right)$. The BMI of less than $18 \mathrm{Kg} / \mathrm{m}^{2}$ is considered as underweight; 18.5-24.9 $\mathrm{Kg} / \mathrm{m}^{2}$ as moderate; $25.0-29.9 \mathrm{Kg} / \mathrm{m}^{2}$ as overweight, and greater than $30 \mathrm{Kg} / \mathrm{m}^{2}$ falls in the category of obese. To evaluate the degree of deficiency regarding thyroid hormones, serum level of (tri-iodothyronine), T4 (thyroxine), and TSH (thyroid stimulating hormone) was recorded using radioimmunoassay techniques (ELISA), Immunoassay test kits. The obtained values of T3, T4, and TSH were analyzed using software IBM SPSS version 20.0 and expressed as means \pm SD.

\section{Results}

In the study total of 204 patients with hypothyroidism were included. BMI was calculated using the height and weight of the patients. The mean and standard deviation was also calculated. The BMI was high in the clinical hypothyroid patients' group, i.e., 26. $84 \pm 4.08$ because of the weight gain, which is a general trend in this group. BMI of subclinical hypothyroid patients was 24.63 \pm 3.51 . However, not much difference was found in values of BMI, which showed the weight increase trend in hypothyroidism (Table 1).

The TFT or thyroid function test for assessment of T3, T4, and TSH was also carried out and compared with standard ranges. The mean value and standard deviations were calculated (Table 1). Decreased values of T3 were found in case of clinical hypothyroidism state $3.97 \pm 3.9 \mu \mathrm{g} / \mathrm{dl}$ and nearly normal values in subclinical sate
$3.55 \pm 5.3 \mu \mathrm{g} / \mathrm{dl}$. Likewise, T4 mean values were lower in hypothyroid patients as compared to normal ranges.

TSH mean values were observed to be significantly increased in case of clinical hypothyroidism $34.69 \pm 13.50 \mathrm{mIU} / \mathrm{L}$ and abnormally high in subclinical hypothyroid patients $7.945 \pm 1.05 \mathrm{mIU} / \mathrm{L}$ shown in Table 1 . The investigation of the age range showed that out of 204 patients, 104 (50.98\%) were between the age range of 20 years to 29 years, $40(19.60 \%)$ between 30 years to 39 years, 27 $(13.23 \%)$ between 40 years to 49 years and $34(16.66 \%)$ were between 50 years to 59 years. The age range from 20 to 29 years was observed to be more vulnerable to have different thyroidal disorders. Based on the gender of hypothyroid patients, women were observed more commonly affected by hypothyroidism than males (Fig. 1 \& Table 2).

The signs and symptoms commonly experienced by hypothyroid patients were depression (83.3\%), weight gain (68\%), constipation $(66 \%)$, muscle pain $(68 \%)$, hair loss (53.4\%), feeling exhausted after sleep $(32 \%)$, neck discomfort $(48 \%)$, in females menstrual irregularities (46\%), hoarseness $(70 \%)$, cold intolerance $(50 \%)$, Skin problem $(48 \%)$ other symptoms were eye pain, dry hair, sleep disturbances, bleeding gums, anxiety, lethargy and loss of appetite, etc. Table 3 shows all the number of cases, symptoms, manifestations, and different demographic features along with percentages, which shows the high prevalence of hypothyroidism in people living in rural areas (Table 3 )

In hypothyroid patients, the prevalence of goiter was observed to be $27 \%$, Hashimotos to be $9 \%$, Thyroid Cancer to be $10 \%$, and Iodine Deficiency to be $88 \%$ and other causes of hypothyroidism include congenital $11 \%$, genetic 18\%, and miscellaneous 39\% respectively (Fig. $2 \&$ Table 4 ). 
Table 1. BMI and thyroid hormones level in the patients

\begin{tabular}{|c|c|c|}
\hline & Subclinical Hypothyroid N=60 & Clinical Hypothyroid $\mathbf{~ = 1 4 4}$ \\
\hline \multirow{2}{*}{ BMI $\left(\mathbf{k g} / \mathbf{m}^{2}\right)$} & Mean \pm SD & Mean \pm SD \\
\cline { 2 - 3 } & $24.63 \pm 3.51$ & $26.84 \pm 4.08$ \\
\hline TSH $(\mathbf{m I U} / \mathbf{L})$ & $7.945 \pm 1.05$ & $34.69 \pm 13.50$ \\
\hline T3 $(\boldsymbol{\mu g} / \mathbf{d l})$ & $3.55 \pm 5.3$ & $3.97 \pm 3.9$ \\
\hline T4 $(\boldsymbol{\mu g} / \mathbf{d l})$ & $12.94 \pm 1.3$ & $15.19 \pm 1.6$ \\
\hline
\end{tabular}

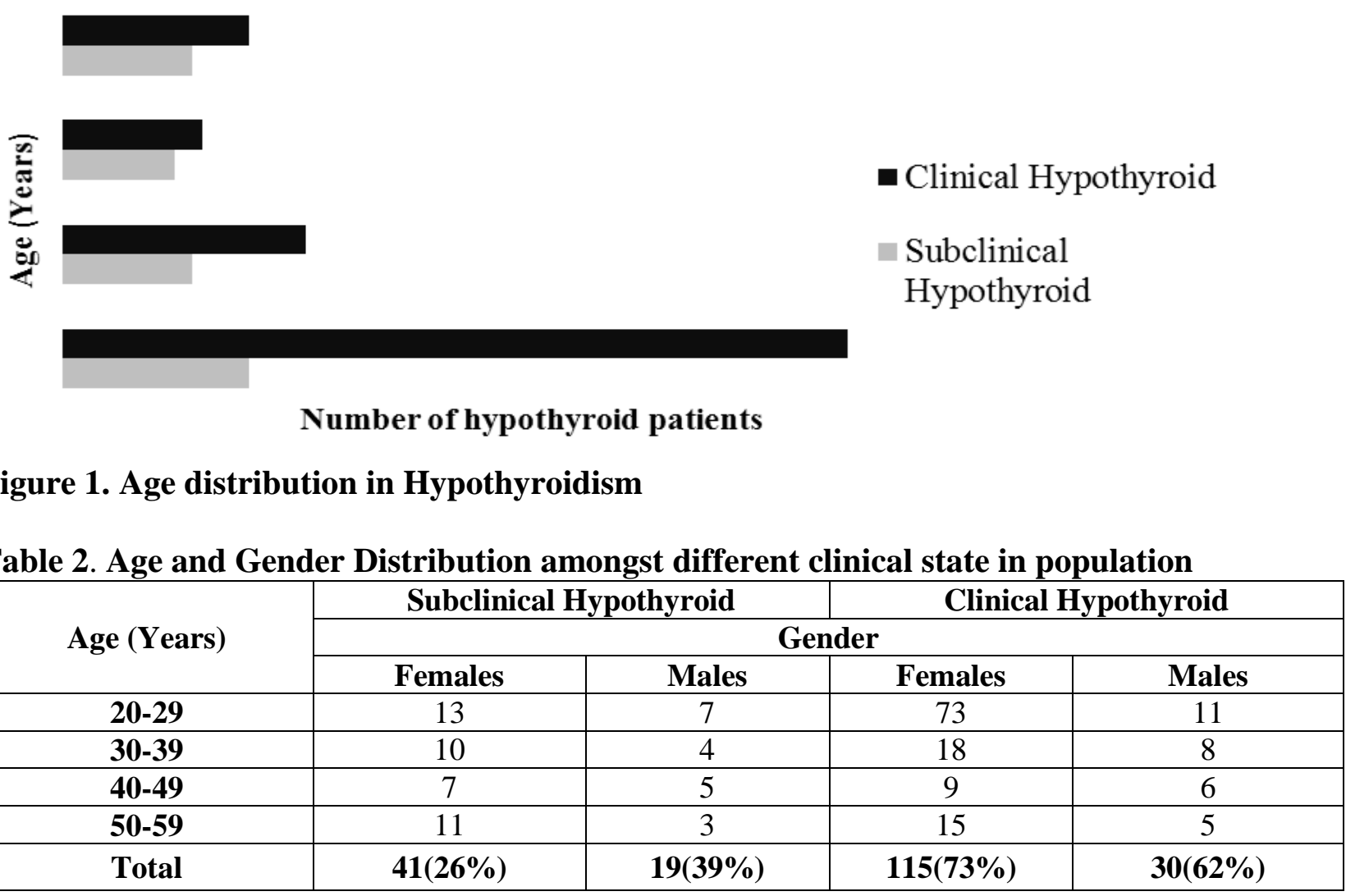

Table 3 Variables of hypothyroid Patients

\begin{tabular}{|c|c|c|}
\hline Demographics and signs & Cases ( N) & Percentage (\%) \\
\cline { 1 - 1 } Location & 142 & 70 \\
\hline Rural & 62 & 30 \\
\hline Urban & 120 & 58.8 \\
\hline Life Style & 84 & 41.1 \\
\hline Sedentary & 167 & 81.8 \\
\hline Active & 37 & 18.1 \\
\hline Feeding habit & 88 & 43.1 \\
\hline Non-Veg & 116 & 56.8 \\
\hline Salt Intake & & \\
\hline Non-Iodinated & Iodinated &
\end{tabular}




\begin{tabular}{|c|c|c|}
\hline Weight Gain & 138 & 68 \\
\hline Skin problem & 24 & 48.98 \\
\hline Bleeding Gum & 71 & 34.80 \\
\hline Throat discomfort & 98 & 48.03 \\
\hline Hair loss & 109 & 53.43 \\
\hline Hoarseness & 143 & 70.09 \\
\hline Cold intolerance & 102 & 50 \\
\hline Obstructive Sleep apnea & 67 & 32.84 \\
\hline Loss of Appetite & 43 & 21.07 \\
\hline Anxiety/Panic attacks & 132 & 64.70 \\
\hline Depression & 170 & 83.3 \\
\hline Muscle aches & 140 & 68.6 \\
\hline Lethargy & 92 & 45 \\
\hline Constipation & 136 & 66.6 \\
\hline Menstrual irregularities & 95 & 46.5 \\
\hline
\end{tabular}

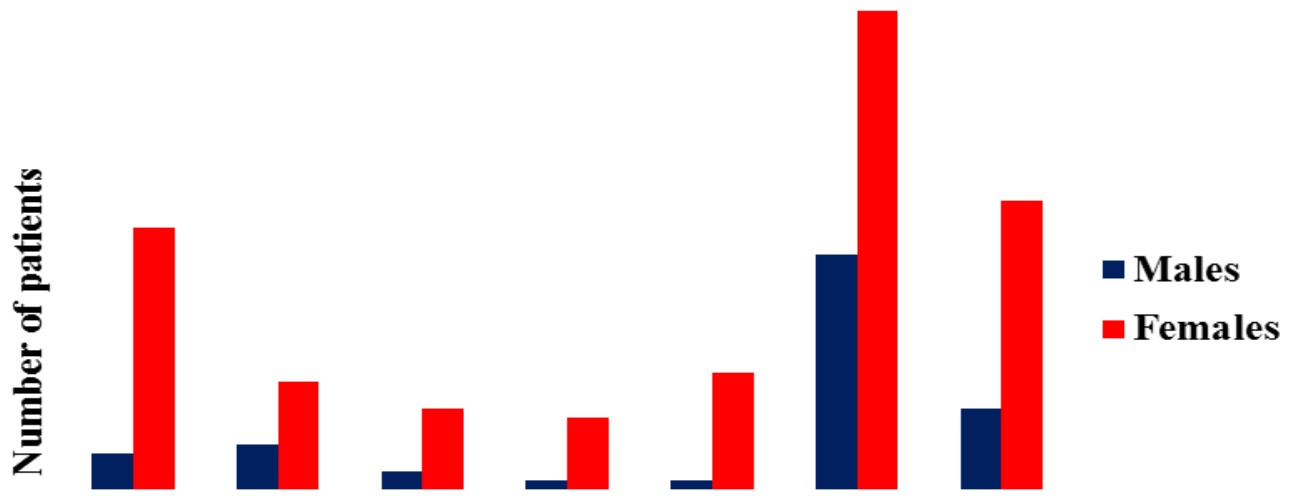

Causes of Disorder

Figure 2. Number of hypothyroid patients presenting different disorders

Table 4. Number of hypothyroid patients representing different disorders

\begin{tabular}{|c|c|c|c|c|}
\hline \multirow{2}{*}{ Cause of Disorder } & \multicolumn{2}{|c|}{ Cases (N) } & \multicolumn{2}{c|}{ Percentage (\%) } \\
\cline { 2 - 5 } & Male & Female & Male & Female \\
\hline Goiter & 4 & 29 & 8.33 & 18.58 \\
\hline Genetic & 5 & 12 & 10.41 & 7.69 \\
\hline Hashimotos & 2 & 9 & 4.16 & 5.76 \\
\hline Thyroid Cancer & 1 & 8 & 2.08 & 5.12 \\
\hline Congenital & 1 & 13 & 2.08 & 8.33 \\
\hline Iodine Deficiency & 26 & 53 & 54.16 & 33.97 \\
\hline Miscellaneous & 9 & 32 & 18.75 & 20.51 \\
\hline Total & $48 / 204$ & $156 / 204$ & 23.53 & 76.4 \\
\hline
\end{tabular}

\section{Discussion}

In mammals for normal growth of the body, its development, and regulation of other normal mechanisms and neuronal differentiation, thyroid hormones are essential to be released in sufficient 
concentration in blood serum [20]. In amphibians, thyroidal hormones are also necessary for metamorphosis [21]. All of these mentioned activities are more evident in the deficient state of thyroid hormone known as hypothyroidism. Events that take place in the dysfunctioning of the thyroid gland are usually due to various contributing factors like demographical division, eating habits, consumption of iodine in the diet, and predisposition or mutation in genes [22].

This research study aims at evaluating the prevalence, clinical manifestation, and pathophysiological features of hypothyroidism in population of Hyderabad, Sindh. This study includes 204 hypothyroid patients, out of which $76 \%$ were females, and $24 \%$ were males, and females were found to be more prone to have hypothyroidism. As per reports, hypothyroidism is more prevalent in females as compared to males. In females, it is found to be $2 \%$ to $5 \%$ with a ratio of 5:1 to males between the age range of 20 years to 40 years [23].

Graphical representation of age distribution showed steepness in peak in the age group of 21 years to 30 years, and graphs showed a decline with the increase in age. Various studies on thyroid dysfunction reported the increase in its prevalence during the middle ages [24]. Many patients with thyroid disorder showed normal TSH levels or only $1 \%$ to $2 \%$ with low serum TSH than normal. In the elderly population of 80 years or more low plasma TSH levels are seen in about 3\% of the population [25].

Several studies also reported a high prevalence of thyroid ailments in Pakistan. As it is considered as iodine deficient area, high rates of thyroid disorders are observed, which may be due to insufficient dietary intake of required iodine, iodized salt or autoimmune disorder leading towards thyroid gland hyper or hypo functionality (hypothyroidism or hyperthyroidism) [26]. On the other hand, in Western and European countries, a high prevalence of hypothyroidism has been observed. In females, high degree points of hypothyroidism due to various factors of gestation are involved, which may be the contributing factors for stimulating autoimmunity in the body. The autoimmune response is observed to produce antibodies causing destruction of the thyroid gland [27]. The nature of most of the thyroid disorders is autoimmunity such as Hashimoto's thyroiditis, Graves's diseases, thyrotoxicosis, goiter, and hypothyroidism [28].

One of the outcomes of abnormal pathophysiology of thyroid gland is goiter. According to the data collected in this study on hypothyroid patients, $27 \%$ of the subjects had a goiter, 9\% had Hashimoto's, 10\% had Thyroid Cancer, and $88 \%$ with Iodine Deficiency with high prevalence in females. The incidence of thyroid maladies and goiter is assessed by multifaceted interaction amongst environmental factors, gender, and genetics. The intake status of iodine is the key environmental factor that verifies goiter dominance [29]. Additionally, the high rate of goiter prevalence in females is attributed by estrogen effect, which is proliferative on the thyroid gland's thyrocyte cells [30].

The common manifestation and symptoms of hypothyroidism include feeling of weakness, coarse and dry skin, constipation, intolerance due to cold, slow or reduced metabolism, anxiety and depression [31]. In hypothyroid patients included in the study presented common symptoms including depression (83.3\%), weight gain (68\%), constipation (66\%), muscle pain (68\%), hair loss (53.4), feeling exhausted after sleep(32\%), neck discomfort $(48 \%)$, in females menstrual irregularities (46), hoarseness $(70 \%)$, cold intolerance (50), Skin problem (48\%) other symptoms were eye pain, dry hair, sleep disturbances, bleeding gums, anxiety, lethargy and loss of appetite, etc. 
The hypothyroid state is also strongly associated with unbalanced levels of lipid consequential towards atherosclerosis. The thyroid hormones and their substrates in hypothyroid conditions promote the utilization of lipid and lipid substances, triggering the high mobility of stored triglycerides in adipose tissue. Clinical hypothyroidism, accompanied by hypertension and hypercholesterolemia, has been associated with various cardiovascular diseases [32].

A study also reported the high subclinical hypothyroidism prevalence among females with a history of myocardial infarction and aortic atherosclerosis. Evidence of thyroid peroxidase antibodies were found in females having these manifestations [33].

\section{Conclusion}

Females are more prone to $b$ at the risk of developing thyroid disorders as compared to the male population. Depression and hypertension is positively associated with hypothyroidism. In order to encounter the issues of thyroid problems, public awareness regarding the importance of dietary intake of iodine is necessary, which can significantly contribute to overcome the increasing prevalence due to deficiency of iodine.

\section{Authors' contributions}

Conceived and designed the experiments: NA Shah, Performed the experiments: N Shah \& NA Shah, Analyzed the data: TJ Ursani, Contributed materials/ analysis/ tools: N Shah \& TJ Ursani, Wrote the paper: N Shah \& HMZ Raza.

\section{References}

1. Bahn RS, Burch HB, Cooper DS, Garber JR, Greenlee MC, Klein IL \& Ross D (2010). Hyperthyroidism: management guidelines of the American Thyroid Association and American Association of Clinical Endocrinologists. Thyroid 1865-1867.

2. Petersen M, Bulow PI, Knudsen N, Andersen S, Jorgensen T, Perrild H \& Carle A (2019). Changes in subtypes of overt thyrotoxicosis and hypothyroidism following iodine fortification. Clin Endocrinol 91(5): 652-659.

3. Bogazzi F, Tomisti L, Bartalena L, Aghini LF \& Martino E (2012). Amiodarone and the thyroid: a 2012 update. J Endocrinol Invest 35(3): 340-348.

4. Pearce EN (2015). Thyroid disorders during pregnancy and postpartum. Best Pract Res Clin Obstet Gynaecol 29(5): 700-706.

5. Ross DS (2011). Radioiodine therapy for hyperthyroidism. $N$ Engl J Med 364(6): 542-550.

6. Menconi F, Marcocci C \& Marino M (2014). Diagnosis and classification of Graves' disease. Autoimmun Rev 13(4-5): 398-402.

7. Rhee CM, Bhan I, Alexander EK \& Brunelli SM (2012). Association between iodinated contrast media exposure and incident hyperthyroidism and hypothyroidism. Arch Intern Med 172(2): 153-159.

8. Santos RB, Romaldini JH \& Ward LS (2012). A randomized controlled trial to evaluate the effectiveness of 2 regimens of fixed iodine (131I) doses for Graves disease treatment. Clin Nucl Med 37(3): 241-244.

9. Kandi S \& Rao P (2012). Anti-thyroid peroxidase antibodies: Its effect on thyroid gland and breast tissue. Ann. Trop Med Pub Heal 5(1): 1.

10. Kitahara CM, Gonzalez AB, Bouville A, Brill AB, Doody MM, Melo DR \& Villoing D (2019). Association of radioactive iodine treatment with cancer mortality in patients with hyperthyroidism. JAMA Intern Med 179(8) 1034-1042.

11. Wong KK, Shulkin BL, Gross MD \& Avram AM (2018). Efficacy of radioactive iodine treatment of graves' hyperthyroidism using a single calculated 131 I dose. Clin Diabetes Endocrinol 4(1): 1-8.

12. Chandna S \& Bathla M (2011). Oral manifestations of thyroid disorders and its management. Indian $J$ Endocrinol Metab $15(2)$.

13. Narayana SK, Woods DR \& Boos CJ (2011). Management of amiodarone-related thyroid problems. Ther Adv Endocrinol Metab 2(3): 115-126.

14. Vanderpump MP (2011). The epidemiology of thyroid disease. Br Med Bull 99(1). 
15. Talat A, Khan AA, Nasreen S \& Wass JA (2019). Thyroid Screening During Early Pregnancy and the Need for Trimester Specific Reference Ranges: A CrossSectional Study in Lahore Pakistan. Cureus 11(9).

16. Sajid N, Riaz M, Fawwad A \& Basit A (2019). Thyroid dysfunction in subjects with type 1 diabetes at a tertiary care unit of Karachi Pakistan. Clin Epidemiol Glob Heal 7(3) 435-438.

17. Ahmad T, Khoja A, Rashid NH \& Ashfaq MA (2018). Outcome of radioactive iodine therapy in Toxic Nodular Goiter in Pakistan. Pak J Pharm Sci 34(5): 1146.

18. Naz N, Rizvi S \& Sadiq Z (2017). Assessment of thyroid hormone levels and thyroid disorders: A case study from Gujranwala Pakistan. Pak J Pharm Sci 30(4).

19. Rehman R, Zafar A, Fatima SS, Mohib A \& Sheikh A (2020). Altered Sperm Parameters and Subclinical hypothyroidism; a cross sectional study in Karachi Pakistan. Int $J$ Clin Pract e13555.

20. Attaullah S, Haq BS \& Muska M (2016). Thyroid dysfunction in khyber pakhtunkhwa pakistan. Pakistan J Med Sci 32(1): 111.

21. Bose A, Sharma N, Hemvani N \& Chitnis DS (2015). A hospital based prevalence study on thyroid disorders in Malwa region of Central India. Int J Curr Microbiol Appl Sci 4(6): 604-611.

22. Seigel SC \& Hodak SP (2012). Thyrotoxicosis. Med. Clin. 96(2) 175-201.

23. Lee SY, Rhee CM, Leung AM, Braverman LE, Brent GA \& Pearce EN (2015). A review: radiographic iodinated contrast media-induced thyroid dysfunction. J Clinic Endo Met 100(2): 376-383.

24. Kibirige D, Luzinda $K$ \& Ssekitoleko $R$ (2013). Spectrum of lithium induced thyroid abnormalities: a current perspective. Thyroid Res 6(1): 1-5.
25. Abraham M, Bystrom K, Torring O, Lantz M, Berg G, Calissendorff J \& Karlsson FA (2011). Incidence of hyperthyroidism in Sweden. Eur J Endocrinol 165(6): 899.

26. Lee H, Hodi FS, Giobbie A, Ott PA, Buchbinder EI, Haq R \& Donahue H (2017). Characterization of thyroid disorders in patients receiving immune checkpoint inhibition therapy. Cancer Immunol Res 5(12): 1133-1140.

27. Deokar PG, Nagdeote AN, Lanje MJ \& Basutkar DG (2016). Prevalence of thyroid disorders in a tertiary care center. Intern $J$ Curr Res Rev 8(9): 26.

28. Kahaly GJ, Bartalena L, Hegedus L, Leenhardt L, Poppe K \& Pearce SH (2018). 2018 European thyroid association guideline for the management of Graves' hyperthyroidism. Eur Thyroid J 7(4): 167186.

29. Rahman MA, Biswas MA, Siddika ST, Sikder AM, Talukder SI \& Alamgir M H (2013). Histomorphological pattern of thyroid lesions. Dinajpur Med Col J 6(2): 134-140.

30. Danzi S \& Klein I (2015). Amiodaroneinduced thyroid dysfunction. Case Rep Med 30(4): 179-185.

31. Piantanida E (2017). Preoperative management in patients with Graves' disease. Gland Surg 6(5): 476.

32. Ogunjobi KO, Ejeh JE, Adedapo KS \& Eniojukan JF (2013). Effectiveness of fixed dose radioactive iodine (RAI) for the treatment of hyperthyroidism: experience of a teaching hospital in South West Nigeria. Mol Imaging Radionucl Ther 22(2): 36.

33. Eftychia GK, Roupas ND \& Markou K B (2017). Effect of excess iodine intake on thyroid on human health. Minerva Med 108(2): 136-146. 